\title{
Genetic and pathogenic diversity of Pseudomonas syringae strains isolated from cucurbits
}

\author{
Renata Slomnicka • Helena Olczak-Woltman • \\ Grzegorz Bartoszewski • \\ Katarzyna Niemirowicz-Szczytt
}

Accepted: 26 August 2014 / Published online: 7 September 2014

(C) The Author(s) 2014. This article is published with open access at Springerlink.com

\begin{abstract}
This work was done to determine the diversity of pathogenic Pseudomonas syringae pv. lachrymans and pv. syringae strains, isolated from cucurbit plants. Pathogenicity tests performed in this work on cucumber indicated that the 22 tested strains differed dramatically in virulence level. Genetic characterization using MLST loci, as well as ITS1, ERIC and REP fingerprinting, allowed the grouping of strains into four phylogenetic groups. After amplicon sequencing and BLAST alignment the collected strains comply with P. syringae pathovars: lachrymans and syringae and with saprophytic $P$. fluorescens. The strains of Pseudomonas syringae pv. lachrymans may be categorized into at least two types differing in both disease symptoms and molecular characteristics. We confirmed that MLST-loci-based grouping of strains corresponds well to grouping based on pathogenicity tests.
\end{abstract}

Keywords Cucurbitaceae Pseudomonas lachrymans . MLST $\cdot$ Molecular differentiation

$\begin{array}{ll}\text { Abbreviations } \\ \text { ALS } & \text { Angular leaf spot } \\ \text { CFU } & \text { Colony forming unit } \\ \text { DSI } & \text { Disease severity index } \\ \text { ERIC } & \text { Enterobacterial repetitive intergenic consensus }\end{array}$

R. Słomnicka $\cdot$ H. Olczak-Woltman $(\bowtie) \cdot G$. Bartoszewski • K. Niemirowicz-Szczytt

Department of Plant Genetics, Breeding and Biotechnology, Warsaw University of Life Sciences, ul. Nowoursynowska 159, 02-776 Warszawa, Poland e-mail: helenaolczak@interia.pl

$\begin{array}{ll}\text { HR } & \text { Hypersensitive reaction } \\ \text { ITS1 } & \text { Inter-genic spacer 1 } \\ \text { MLST } & \text { Multi-locus sequence typing } \\ \text { pv. } & \text { Pathovar } \\ \text { REP } & \text { Repetitive extragenic palindromic sequences } \\ \text { RH } & \text { Relative humidity }\end{array}$

\section{Introduction}

Pseudomonas syringae pv. lachrymans, a pathogen of cucumber (Cucumis sativus L.), is one of the pathovars belonging to the heterogeneous bacteria species Pseudomonas syringae (Young et al. 1996). It causes angular leaf spot (ALS), a very common cucumber disease. The symptoms of ALS consist of vein-limited water-soaked lesions, which later become necrotic, resulting in significant yield reduction (Bradbury 1986). Although this disease is ascribed to a single pathovar, there are numerous strains of this pathovar that vary from each other at biological, biochemical and genetic levels. Moreover, similar symptoms on cucumber may be caused by strains belonging to pathovar syringae (Olczak-Woltman et al. 2007).

Recent studies of $P$. syringae reveal that various strains differ dramatically in genome size, GC content, plasmid presence, and pathogenesis-related gene repertoire including effector-encoding genes (Baltrus et al. 2011; O'Brien et al. 2011). These variations illustrate P. syringae genome plasticity and indicate the dynamic nature of this species. Analysis of the $16 \mathrm{~S}$ variable 
region and of the Intergenic Spacer 1 (ITS1) region used to be commonly employed in bacterial strain differentiation and identification. In addition, intraspecific typing of bacteria can be done using the Multi-locus Sequence Typing (MLST) method. MLST is preferred for determination of genomic relatedness among bacterial strains because it allows comparison of sequences of housekeeping genes that encode proteins necessary for the microorganism's survival (Maiden et al. 1998; Urwin and Maiden 2003). MLST can be applied to Pseudomonas syringae (Sarkar and Guttman 2004). Another approach allowing bacterial isolate identification is based on PCR amplification of bacterial repetitive sequences (rep-PCR technique). In this approach Enterobacterial Repetitive Intergenic Consensus (ERIC) sequences and Repetitive Extragenic Palindromic (REP) sequences are analyzed. These are short, repetitive DNA sequences with highly conserved central inverted repeats that are dispersed throughout the genomes of diverse bacterial species (Versalovic et al. 1991). Designing universal rep-PCR primers (ERIC and REP) allows generation of highly reproducible fingerprints that can differentiate strains below the level of species (Louws et al. 1994).

The aim of this study was to determine the genetic diversity among strains of Pseudomonas sp. collected from different cucurbit plants using the MLST method, ITS1 and rep-PCR primers. The molecular identification was verified by pathogenicity tests performed on cucumber and tobacco plants. Additionally, the aim of this study was to determine an efficient molecular technique for identification of various strains of $P$. syringae $\mathrm{pv}$. lachrymans. We also looked for presence of plasmids in the collected bacterial strains and investigated whether there was a correlation between the plasmid's presence and the strain's increased pathogenicity and/or virulence.

\section{Materials and methods}

Bacterial strains The bacterial collection consisted of 22 Pseudomonas strains. Nine strains were isolated from cucumber leaves that were showing angular leaf spot symptoms, collected in Poland (Olczak-Woltman et al. 2007). The others were obtained from the European bacterial culture collections (Table 1). All strains were stored on nutrient agar slopes at $4{ }^{\circ} \mathrm{C}$ and only pure cultures were used in molecular analysis and assays.

Cucumber pathogenicity and virulence tests To verify the strain pathogenicity on cucumber and to define the virulence level, the seeds of susceptible to ALS Cucumis sativus inbred line B, selected from variety 'Borszczagowski', were individually sown into plastic pots filled with peat moss. The plants were maintained in a growth chamber at $25^{\circ} \mathrm{C}$ during the day and $22{ }^{\circ} \mathrm{C}$ at night, with $16 \mathrm{~h}$ illumination under high pressure sodium lamps providing light intensity of $50 \mathrm{~W} \mathrm{~m}^{-2}$. Inoculum was prepared by growing bacterial cells for $24 \mathrm{~h}$ on King B agar plates at $28{ }^{\circ} \mathrm{C}$ in the dark. The resulting colonies were suspended in sterile distilled water and adjusted to $\mathrm{OD}_{600}=0.050$ previously established to be equal to concentration of $1 \times$ $10^{7} \mathrm{CFU} \mathrm{ml}{ }^{-1}$. Cucumber plants at the 2nd to 3rd leaf stage were inoculated by spraying the abaxial side of each leaf (Klement et al. 1990). Sterile water was used as a control. After inoculation, plants were kept in the dark at $100 \% \mathrm{RH}$ for $24 \mathrm{~h}$, and then for 6 days in the growth chamber under light and with $90 \%$ relative humidity. After 7 days, inoculated leaves were scored for disease severity and appearance of symptoms. The evaluation using a 1-9 disease severity index (DSI) where the most resistant plants were given the score of nine and the most susceptibility plants were given the score of one, was performed according to the protocol previously described (Olczak-Woltman et al. 2008). The pathogenicity tests of each strain were performed using a total of 24 plants (with four replications of six plants in each replication).

Pathogenicity verification The strain pathogenicity was verified using Nicotiana benthamiana as a host. The seeds of $N$. benthamiana were sown into plastic pots filled with peat moss. The growth chamber conditions and bacterial inoculum preparation were the same as for the cucumber pathogenicity and virulence tests. Nineweeks-old tobacco plants were inoculated by infiltration of the abaxial side of each leaf (five separate points per leaf) with bacterial suspension. Infiltration using sterile water was used as a control. Each strain was tested on a separate tobacco plant. Additionally, some tobacco plants were inoculated with four different strains on the same leaf. Plants were kept in the dark at $100 \%$ relative humidity for $24 \mathrm{~h}$, and then for $48 \mathrm{~h}$ in the chamber with light $\left(50 \mathrm{~W} \mathrm{~m}^{-2}\right)$ and $90 \%$ relative 
Table 1 Bacterial culture collection - name, place and plant of isolation, the HR results on tobacco and cucumber pathogenicity and virulence tests with DSI and symptoms description

\begin{tabular}{|c|c|c|c|c|c|c|c|c|}
\hline \multirow[t]{2}{*}{ No } & \multirow[t]{2}{*}{ Strain's name \& pathovar } & \multicolumn{2}{|c|}{ Source of strain } & \multirow[t]{2}{*}{ HR on tobbaco } & \multicolumn{4}{|c|}{ Pathogenicity on cucumber } \\
\hline & & country & species & & $P$ & $V$ & $D S I$ & Symptoms description \\
\hline 1 & Ps1 814/98 & Holland & cucumber & + & + & $* * *$ & 4,0 & water-soaked, bacterial ooze \\
\hline 2 & Psl CCM2857 & Czech Rep & cucumber & + & + & $* * *$ & 4,0 & water-soaked, bacterial ooze \\
\hline 3 & Ps1 BG283 & Holland & cucumber & - & + & $*$ & 8,1 & few chlorotic lesions \\
\hline 4 & Psl BG966 & Holland & cucumber & + & + & $* *$ & 5,5 & necrotic and chlorotic lesions \\
\hline 5 & Psl LMG5070 & Belgium & cucumber & + & + & $* *$ & 5,3 & necrotic and chlorotic lesions \\
\hline 6 & Pss 2905 & Poland & stone fruits & + & + & $* *$ & 6,5 & tiny, chlorotic/necrotic lesions \\
\hline 7 & Pss BG913 & Holland & cucumber & + & + & $* *$ & 5,9 & pinpoint, chlorotic lesions, \\
\hline 8 & Pss CCB37/09 & Czech Rep & cucumber & + & + & $* *$ & 6,6 & dry, papery, necrotic lesions \\
\hline 9 & Pss CCM2858 & Czech Rep & watermelon & + & + & $* * *$ & 3,8 & large necrotic lesions \\
\hline 10 & Pss PD2021 & Italy & pumpkin & + & + & $* *$ & 6,8 & dry, papery, necrotic lesions \\
\hline 11 & Pss WK1/02 & Poland & cucumber & + & + & $* *$ & 5,9 & dry, papery, necrotic lesions \\
\hline 12 & Pss WW4/02 & Poland & cucumber & + & + & $*$ & 8,3 & few chlorotic lesions \\
\hline 13 & Pss WW17/01 & Poland & cucumber & + & + & $* *$ & 6,5 & pinpoint, chlorotic lesions \\
\hline 14 & Pss WW27/01 & Poland & cucumber & + & + & $* *$ & 6,4 & pinpoint, chlorotic lesions \\
\hline 15 & Pss WW254/2 & Poland & cucumber & + & + & $* *$ & 5,3 & pinpoint, chlorotic lesions \\
\hline 16 & P.sp. PD3662 & Holland & cucumber & + & + & $*$ & 7,1 & limited necrotic lesions, halo \\
\hline 17 & P.sp.WH6/01 & Poland & cucumber & + & + & $*$ & 7,5 & limited necrotic lesions, halo \\
\hline 18 & P.sp.WM2/02 & Poland & cucumber & + & + & $*$ & 7,6 & limited necrotic lesions, halo \\
\hline 19 & P.sp.YPG1293 & Holland & cucumber & + & + & $*$ & 7,5 & limited necrotic lesions, halo \\
\hline 20 & Pf PD2760 & Italy & Cucumis sp. & - & + & $*$ & 8,0 & limited chlorotic lesions \\
\hline 21 & Pf WH1/01 & Poland & cucumber & - & + & $*$ & 8,4 & limited chlorotic lesions \\
\hline 22 & Pf WH2/01 & Poland & cucumber & - & + & $*$ & 8,4 & limited chlorotic lesions \\
\hline
\end{tabular}

Strain's sources: strains 814/98 and YPG1293 of Dutch origin were obtained from the Institute of Plant Protection, Poznan, Poland. Strain LMG5070 was obtained from the Microbiology Laboratory in Gent, Belgium. Strains BG283, BG913, and BG966 were obtained from the Nunhems Netherlands, Haelen, The Netherlands. Strains CCB37/09, CCM2857, and CCM2858 were obtained from AGRI, Olomouc, Czech Republic. Strains PD2021 and PD2760 of Italian origin and strain PD3662 of Dutch origin were obtained from the National Reference Centre, Plant Protection Service, Wageningen, The Netherlands. Strain 2905 of P. syringae pv. syringae was obtained from the Research Institute of Pomology and Floriculture in Skierniewice, Poland. Nine strains were isolated from cucumber leaves that were showing angular leaf spot symptoms, and were collected in central and southern (WW, WM and WK, WH, respectively) Poland (OlczakWoltman et al. 2007)

The abbreviations of the species/pathovars names before the laboratory collections numbers means: Psl - Pseudomonas syringae pv. lachrymans; Pss - Pseudomonas syringae pv. syringe; Pf - Pseudomonas fluorescens; P.sp. - Pseudomonas sp.;

HR on tobacco $=$ hypersensitivity reaction on N.benthamiana $(+)=$ HR present, and $(-)=$ no HR. $P=$ pathogenicity on susceptible cucumber accession line B. $(+)=$ symptoms present, and $(-)=$ no symptoms. $V=$ the virulence level. $* * *=$ highly virulent strain, $* *=$ average level of virulence $^{*}=$ low virulent strain. $D S I=$ disease severity index, where $9=$ no symptoms, and $1=$ the maximum of symptoms. Each strain was tested on 24 plants of susceptible cucumber accession line B, and the DSI is an average score of these 24 scores

humidity. The lesions were scored for the presence of hypersensitive reaction (HR) $3 \mathrm{~d}$ after inoculation.

Bacterial DNA isolation After growing the cultures for $24 \mathrm{~h}$ in LB liquid medium on a rotary shaker at $28^{\circ} \mathrm{C}$, total genomic DNA was extracted from $1 \mathrm{ml}$ of culture using the DNA Genomic-tips 100/G kit (Qiagen, Germany), following the manufacturer's instructions. The DNA concentration was estimated by electrophoresis of $2 \mu \mathrm{l}$ DNA, together with a DNA marker, on a $1 \%$ agarose gel with $1 \times$ TEA buffer and stained with ethidium bromide.

Plasmid detection Plasmid bands were detected and visualised using Eckhardt gel electrophoresis technique 
(Eckhardt 1978; modified by Maj et al. 2013). The bacterial cultures were grown overnight in LB liquid medium on a rotary shaker at $28{ }^{\circ} \mathrm{C}$. The free-living cells contained in $1 \mathrm{ml}$ of $\mathrm{LB}$ culture at $\mathrm{OD}_{620}=0.20$ were harvested by centrifugation. The pellet was suspended in $0.5 \mathrm{ml}$ of cold water and layered onto $1 \mathrm{ml}$ of ice-cold $0.3 \%$ sodium sarcosinate, centrifuged again, and the pellet was resuspended in the mixture $(40 \mu \mathrm{l})$ of $10 \mathrm{mM}$ Tris- $\mathrm{HCl}, 10 \mathrm{mM}$ EDTA, and $20 \%$ Ficoll (MT 400 000). The samples were held on ice for $10 \mathrm{~min}$. A $0.75 \%$ agarose gel with $0.5 \times$ TBE buffer was prepared by loading $25 \mu \mathrm{l}$ of $10 \%$ SDS containing xylene cyanole $\mathrm{FF}\left(1 \mathrm{mg} \mathrm{m}^{-1}\right)$ into each origin slot and backtracking at $100 \mathrm{~V}$ for $30 \mathrm{~min}$. Next, $10 \mu \mathrm{l}$ of lysis solution $(10 \mathrm{mM}$ Tris-HCl, $10 \mathrm{mM}$ EDTA, $0.4 \mathrm{mg} \mathrm{ml}^{-1}$ boiled RNase type $\mathrm{A}, 1 \mathrm{mg} \mathrm{ml}^{-1}$ lysosyme, and $1 \mathrm{mg} \mathrm{ml}^{-1}$ bromophenol blue) was mixed with each sample. Then $25 \mu$ of such sample was loaded into the gel. The electrophoresis was run for $15 \mathrm{~h}$ and the gel was strained with ethidium bromide $\left(0.5 \mu \mathrm{g} \mathrm{ml}^{-1}\right)$ for $20 \mathrm{~min}$. Strain 1448A of P.syringae pv. phaseolicola, that contains two plasmids of known size (Joardar et al. 2005), was used as a positive control in plasmids visualization on the gel.

Amplification of the ITS1 region DNA amplification was performed using D21 and D22 primers (Manceu and Horvais 1997) according to the protocol of Sorensen et al. (1998) with modifications of OlczakWoltman et al. (2007). The PCR amplifications were performed using a PTC-200 thermocycler (MJ Research, USA) with the following parameters: template denaturation at $94{ }^{\circ} \mathrm{C}$ for $1.5 \mathrm{~min}$, primer annealing at $62{ }^{\circ} \mathrm{C}$ for $1 \mathrm{~min}$, and DNA extension for $2 \mathrm{~min}$ at $72{ }^{\circ} \mathrm{C}$. The PCR was repeated for 30 cycles, with a final extension step of $10 \mathrm{~min}$ at $72{ }^{\circ} \mathrm{C}$. Amplicons were detected by electrophoresis on a $1 \%$ agarose gels with $0.5 \times$ TBE buffer, stained with ethidium bromide and photographed using an UV trans-illuminator.

Amplification of the selected MLST loci Identification of $P$. syringae pv. lachrymans strains was done by PCR amplification using primers for the following housekeeping genes: aconitate hydratase B $(\operatorname{acn} B)$, citrate synthase (cts), glyceraldehyde-3-phosphate dehydrogenase $(\operatorname{gap} A)$, gyrase B $(g y r B)$, phosphofructokinase ( $p f k$ ), phosphoglucoisomerase (pgi) (Sarkar and Guttman 2004; Hwang et al. 2005). In addition, we performed an amplification of harpin elicitor ( $h r p Z$ )
(Inoue and Takikawa 2006) using the same conditions as for the MLST loci. The characteristics of the used MLST loci and the harpin elicitor, i.e. the name, encoding protein, melting temperature, length, primer sequence, amplicon length and the author are listed in Table 2. Reactions (repeated twice) were carried out for all strains in the collection, in the same PCR and detection conditions as described for amplification of the ITS1 region.

Amplicons sequencing The successful PCR reactions, in which the resulting target PCR product was obtained, were collected and commercially sequenced (Genomed, Poland). Contigs were assembled using Sequencher 4.5 Software (Gene Codes, USA). Consensus sequences were submitted to the GenBank and accession numbers are provided in Table 3.

Strain differentiation using ERIC and REP fingerprinting Primer sequences corresponding to ERIC elements (ERIC1R: 5'-ATGTAAGCTCCTGGGGATTCAC-3' and ERIC2: 5'-AAGTAAGTGACTGGGGTGAGCG$\left.3^{\prime}\right)$ and corresponding to REP elements (REP1R-I: 5-' IIIICGICGICATCIGGC-3' and REP2-I: 5'-ICGICTTA TCIGGCCTAC-3') were used (De Bruijn 1992). The reaction mixture $(20 \mu \mathrm{l})$ consisted of $10 \times$ Dream Taq buffer (Thermo Scientific, Lithuania), $0.4 \mu \mathrm{M}$ of dNTPs Mix, $0.75 \mu \mathrm{M}$ of each primer, $1.0 \mathrm{U}$ of DreamTaq DNA polymerase and $4 \mu \mathrm{l}$ of bacterial suspension. The PCR amplifications were performed in a PTC-200 thermocycler (MJ Research, USA) with the following parameters: initial denaturation at $95{ }^{\circ} \mathrm{C}$ for $7 \mathrm{~min}$, template denaturation at $94{ }^{\circ} \mathrm{C}$ for $1 \mathrm{~min}$, primer annealing at $52{ }^{\circ} \mathrm{C}$ (ERIC) or at $41{ }^{\circ} \mathrm{C}$ (REP) for $1 \mathrm{~min}$, and DNA extension for $8 \mathrm{~min}$ at $65{ }^{\circ} \mathrm{C}$. The PCR was repeated for 30 cycles, with a final extension step of $15 \mathrm{~min}$ at $65{ }^{\circ} \mathrm{C}$. Amplicons were detected by electrophoresis on a $1.5 \%$ agarose gels with $0.5 \times$ TBE buffer, stained with ethidium bromide and photographed using a digital camera and a UV trans-illuminator.

Data analysis Polymorphisms generated by MLST and ITS1 in PCR reactions and visualised after sequencing were analysed using Geneious R7 software (Biomatters, USA). Genetic similarity (\%) among the bacterial strains was calculated and the alignments were made using ClustalW method. Dendrograms were constructed using UPGMA clustering method. Polymorphisms generated by ERIC- and REP- PCR reactions were analysed 
Table 2 The ITS1, hrpZ gene fragment and MLST primers used in this study

\begin{tabular}{|c|c|c|c|c|c|}
\hline $\begin{array}{l}\text { Name of the amplified } \\
\text { region }\end{array}$ & $\operatorname{Tm}\left({ }^{\circ} \mathrm{C}\right)$ & Length (bp) & Sequence $\left(5^{\prime} \rightarrow 3 \sim^{\prime}\right)$ & $\begin{array}{l}\text { Amplicon } \\
\text { length (bp) }\end{array}$ & Reference \\
\hline \multirow[t]{2}{*}{$16 \mathrm{~S}-23 \mathrm{~S}$ ITS } & 54 & 20 & AGCCGTAGGGGAACCTGCGG & \multirow[t]{2}{*}{$550-574$} & \multirow[t]{2}{*}{ Manceu and Horvais (1997) } \\
\hline & 50 & 20 & TGACTGCCAAGGCATCCACC & & \\
\hline \multirow[t]{2}{*}{ acn } & 60 & 23 & ACATCCCGCTGCACGCYCTGGCC & \multirow[t]{2}{*}{626} & \multirow[t]{2}{*}{ Sarkar and Guttman (2004) } \\
\hline & 60 & 24 & GTGGTGTCCTGGGAACCGACGGTG & & \\
\hline \multirow[t]{2}{*}{$c t s(g l t)$} & 64 & 24 & GCCTCBTGCGAGTCGAAGATCACC & \multirow[t]{2}{*}{$949-667$} & \multirow[t]{2}{*}{ Hwang et al. (2005) } \\
\hline & 62,8 & 24 & CTTGTAVGGRCYGGAGAGCATTTC & & \\
\hline \multirow[t]{2}{*}{ gap $A$} & 62 & 16 & CGCCATYCGCAACCG & \multirow[t]{2}{*}{681} & \multirow[t]{2}{*}{ Sarkar and Guttman (2004) } \\
\hline & 62 & 19 & CCCAYTCGTTGTCGTACCA & & \\
\hline \multirow[t]{2}{*}{$\operatorname{gyr} B$} & 62,9 & 23 & TCBGCRGCVGARGTSATCATGAC & \multirow[t]{2}{*}{703} & \multirow[t]{2}{*}{ Hwang et al. (2005) } \\
\hline & 60,7 & 23 & TTGTCYTTGGTCTGSGAGCTGAA & & \\
\hline \multirow[t]{2}{*}{ hrpZ } & 60 & 20 & TTGGCTCAAGAGTTGACCCG & \multirow[t]{2}{*}{810} & \multirow[t]{2}{*}{ Inoue and Takikawa (2006) } \\
\hline & 60 & 20 & GCGCGTTGACCAGCAAGTTG & & \\
\hline \multirow[t]{2}{*}{$p g i$} & 60 & 25 & TGCAGGACTTCAGCATGCGCGAAGC & \multirow[t]{2}{*}{$559-589$} & \multirow[t]{2}{*}{ Sarkar and Guttman (2004) } \\
\hline & 60 & 25 & CGAGCCGCCCTGSGCCAGGTACCAG & & \\
\hline \multirow[t]{2}{*}{$p f k$} & 63 & 20 & ACCMTGAACCCKGCGCTGGA & \multirow[t]{2}{*}{$785-815$} & \multirow[t]{2}{*}{ Sarkar and Guttman (2004) } \\
\hline & 63 & 20 & ATRCCGAAVCCGAHCTGGGT & & \\
\hline \multirow[t]{2}{*}{ rpoD } & 63 & 25 & AAGGCGARATCGAAATCGCCAAGCG & \multirow[t]{2}{*}{532} & \multirow[t]{2}{*}{ Sarkar and Guttman (2004) } \\
\hline & 63 & 25 & GGAACWKGCGCAGGAAGTCGGCACG & & \\
\hline
\end{tabular}

$16 \mathrm{~S}-23 \mathrm{~S}$ ITS1 $=$ - the $16 \mathrm{~S}-23 \mathrm{~S}$ intergenic spacer region, $a c n=$ aconitate hydratase, $c t s=(g l t)$ citrate synthase, gap $A=$ glyceraldehyde- 3 phosphate dehydrogenase, $g y r B=$ gyrase $\mathrm{B}$, hrpZ $=$ harpin $h r p Z$, $p g i=$ glucose-6-phosphate isomerase, $p f k=1$-phosphofructokinase, rpo $D=$ sigma factor 70

using GelCompar II v.6.6 software (Applied Maths, USA). Genetic similarity (\%) of bacterial strains patterns was calculated using the Dice coefficient and a dendrogram was constructed using the UPGMA clustering method.

Sequences were aligned to genome sequences of P. syringae strains collected in the JGI database (DOE Joint Genome Institute, USA) using BLAST algorithm.

\section{Results}

Hypersensitivity reaction on tobacco leaves All but four strains produced a HR on $N$. benthamiana leaves $3 \mathrm{~d}$ after infiltration, confirming their pathogenicity (Table 1, Fig. 1). Strains BG283, PD2760, WH1/01, and $\mathrm{WH} 2 / 01$ did not produce a HR on tobacco.

Pathogenicity and virulence tests on cucumber leaves The bacterial strains exhibited diverse pathogenicity and virulence levels when tested on susceptible cucumber accession line B (Fig. 2 a-f). P. syringae pv. lachrymans strains $814 / 98$ and CCM2857 were the most virulent and caused typical angular leaf spot symptoms on cucumber leaves, i.e. water-soaked, later necrotic lesions with a large chlorotic halo, as well as the bacterial ooze on the abaxial side of the inoculated leaves (Fig. 2a). P. s. pv. lachrymans strains LMG5070 and BG966 were far less virulent on cucumber leaves, causing fast drying water-soaked lesions, and dry, lightcoloured, papery lesions, with numerous pinpoint chlorotic lesions (Fig. 2b). Strain CCM2858 was a very virulent one, causing characteristic drying of the part of cucumber leaf, but although the lesions were very large in size, they differed dramatically from the lesions caused by other strains. Strain 2905 of pathovar syringae and strains BG913, WW17/01, WW27/01, and WW254/02 caused numerous pinpoint chlorotic or light-coloured necrotic lesions on cucumber leaves. In the case of strain BG913, these symptoms were the most severe, and in case of WW17/01 and WW27/01 less severe (Fig. 2d). Similar symptoms were caused by LMG5070 and BG966 strains. Strains CCB37/09, PD2021, and WK1/02 caused on cucumber large, dry, light-coloured necrotic lesions without chlorosis (Fig. 2e). Similar lesion, although smaller in size, were caused by strains PD3662, WH6/01, WM2/02, and YPG1293. Strains BG283 (Fig. 2c), PD2760, WH1/ 01, WH2/01 (Fig. 2f), and WW4/02 produced only very weekly chlorotic lesions, HR reactions, or did not produce any symptoms on cucumber leaves. 
Table 3 Consensus sequences submitted to the NCBI GenBank with accession numbers

\begin{tabular}{|c|c|c|c|c|c|c|c|c|c|}
\hline Strain name & $\begin{array}{l}16 \mathrm{~S}-23 \mathrm{~S} \\
\text { ITS }\end{array}$ & $\begin{array}{l}\text { acn partial } \\
\text { sequence }\end{array}$ & $\begin{array}{l}\text { cts partial } \\
\text { sequence }\end{array}$ & $\begin{array}{l}\text { gap } A \text { partial } \\
\text { sequence }\end{array}$ & $\begin{array}{l}\text { gyrB partial } \\
\text { sequence }\end{array}$ & $\begin{array}{l}\text { hrpZ partial } \\
\text { sequence }\end{array}$ & $\begin{array}{l}p f k \text { partial } \\
\text { sequence }\end{array}$ & $\begin{array}{l}\text { pgi partial } \\
\text { sequence }\end{array}$ & $\begin{array}{l}r p o D \text { partial } \\
\text { sequence }\end{array}$ \\
\hline Psl 814/98 & HQ171969 & KJ158838 & KJ158857 & HQ171970 & KJ158888 & HQ171971 & KJ158909 & KJ158926 & KJ158944 \\
\hline PslCCM2857 & & KJ158839 & KJ158858 & JN624869 & KJ158889 & JN624876 & KJ158910 & & KJ158945 \\
\hline Ps1 BG283 & & & KJ158859 & KJ158878 & KJ158890 & JN624875 & & KJ158927 & KJ158946 \\
\hline Psl BG966 & JN624859 & KJ158842 & KJ158862 & JN624867 & KJ158893 & & KJ158913 & KJ158930 & KJ158949 \\
\hline PslLMG5070 & JN624860 & KJ158841 & KJ158861 & JN624868 & KJ158892 & & KJ158912 & KJ158929 & KJ158948 \\
\hline Pss 2905 & JN624865 & KJ158855 & KJ158876 & JN624874 & KJ158908 & & KJ158924 & KJ158942 & KJ158965 \\
\hline Pss BG913 & & KJ158844 & KJ158865 & JN624866 & KJ158896 & & KJ158916 & KJ158932 & KJ158952 \\
\hline PssCCB37/09 & & KJ158846 & KJ158867 & KJ158879 & KJ158898 & & KJ158917 & & KJ158954 \\
\hline PssCCM2858 & JN624861 & KJ158843 & KJ158864 & JN624870 & KJ158895 & & KJ158915 & KJ158933 & KJ158951 \\
\hline Pss PD2021 & JN624862 & & KJ158863 & JN624871 & KJ158894 & & KJ158914 & KJ158931 & KJ158950 \\
\hline Pss WK1/02 & & KJ158851 & KJ158872 & KJ158884 & KJ158902 & & KJ158921 & KJ158938 & KJ158959 \\
\hline Pss WW4/02 & & KJ158850 & KJ158871 & KJ158883 & KJ158901 & & KJ158920 & & KJ158958 \\
\hline PssWW17/01 & & KJ158854 & & KJ158886 & KJ158905 & & & KJ158940 & KJ158962 \\
\hline PssWW27/01 & & KJ158849 & KJ158870 & KJ158882 & KJ158900 & & KJ158919 & KJ158937 & KJ158957 \\
\hline PssWW254/02 & & KJ158853 & KJ158874 & KJ158885 & KJ158904 & & KJ158923 & KJ158939 & KJ158961 \\
\hline P.sp.PD3662 & & KJ158840 & KJ158860 & & KJ158891 & JN624877 & KJ158911 & KJ158928 & KJ158947 \\
\hline P.sp.WH6/01 & & & KJ158869 & KJ158881 & KJ158899 & & KJ158918 & KJ158936 & KJ158956 \\
\hline P.sp.WM2/02 & & KJ158852 & & & KJ158903 & & KJ158922 & & KJ158960 \\
\hline P.sp.YPG1293 & JN624863 & KJ158856 & KJ158877 & JN624872 & KJ158906 & & KJ158925 & KJ158943 & KJ158964 \\
\hline Pf PD2760 & JN624864 & KJ158845 & KJ158866 & JN624873 & KJ158897 & & & KJ158934 & KJ158953 \\
\hline Pf WH1/01 & & KJ158847 & KJ158868 & KJ158880 & & & & KJ158935 & KJ158955 \\
\hline Pf WH2/01 & HQ171972 & KJ158848 & KJ158873 & HQ171973 & & & & & \\
\hline
\end{tabular}

Amplification of the ITS1 region Amplification of the 16S-23S ITS1 region allowed us to obtain amplicons of 560-574 bp long in all strains. However, despite of several attempt sequencing of this fragment was possible only in case of 10 out of 22 strains.

Amplification of the hrpZ gene fragment Amplification of the hrpZ gene fragment produced $810 \mathrm{bp}$ long amplicon. However, despite several attempts, this fragment was obtained and sequenced for only four strains: 814/98, BG283, CCM2857, and PD3662.

Amplification of the MLST loci Amplification of the 7 MLST loci resulted in informative amplicons that further facilitated grouping of strains. The obtained amplicons ranged from 530 to $970 \mathrm{bp}$, depending on the MLST locus (Table 2). Although the obtained amplicon quality was satisfactory, in the case of acn, $p g i$, and $r p o D$ amplification failed in 1 strain, in case of gyrB and $p f k$ - in 2 strains; in case of gapA - amplification of 3 strains failed. Amplicons for $c t s$ were obtained in all strains. The obtained amplicons were sequenced and the consensus sequences of all alleles were submitted to the NCBI GenBank (the consensus sequences symbols and numbers are provided in Table 3).

Strains differentiation by ERIC and REP fingerprinting ERIC and REP showed significant diversity in the banding patterns of all strains. Each pattern consisted of approximately 11-22 bands, ranging in size from 130 to over 3,000 bp. The strains' banding patterns differed from each other, although in case of ERIC (Figs. 4 and 5) and REP (data not shown) strains LMG 5070 and BG966 showed identical band patterns.

Sequences alignment The obtained ITS1, hrpZ, and MLST sequences were aligned to sequences deposited in the JGI base. The alignment of 10 obtained ITS1 amplicons allowed us to divide strains into four groups. 


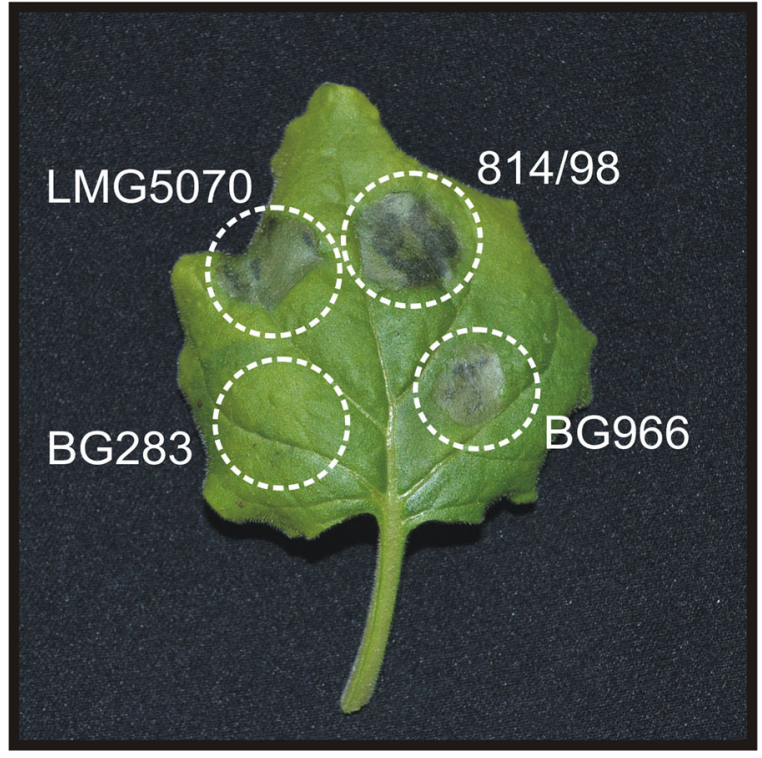

Fig. 1 The results of the HR test performed on Nicotiana benthamiana with visualisation of differences in pathogenicity. A tobacco leaf three days after infiltration. This leaf was infiltrated with four different strains, all classified as P.s. pv. lachrymans: $814 / 98$ of high virulence level, LMG5070 and BG966 of medium virulence level, and BG283 of low virulence level

Based on the ITS1 loci analysis, strain 814/98 exhibited $99 \%$ of genetic similarity to lachrymans strain Pla107 deposited in the JGI base. Strains LMG5070 and BG966 showed the highest genetic similarity to lachrymans strain Pla106. Strains CCM2858, PD2021, and WW4/ 02 exhibited the highest genetic similarity to strains of pathovar syringae, and the referenced strain 2905 confirmed its classification in this pathovar. Strains
PD2760, WH1/01, and WH2/01 turned to be similar to Pseudomonas fluorescens.

The hrpZ amplicons were obtained only for strains 814/98, BG283, CCM2857, and PD3662. The alignment to the sequences deposited in the JGI database suggested that all these strains belong to pathovar lachrymans. In the case of 814/98 and CCM2857 the alignment indicated the highest similarity to lachrymans strain Pla107.

The MLST alignment allowed a very accurate strain grouping. All obtained MLST amplicons classified strains into the same pathovar, either lachrymans or syringae, or into P.fluorescens. Strain 814/98 according to loci $\operatorname{gap} A, \operatorname{gyr} B, \mathrm{rpoD}, \mathrm{cts}$, acn, pgi, and pfk was classified as pathovar lachrymans, with the highest similarity to strain Pla107. The same results were obtained for CCM2857, except that for locus pgi an amplicon was not generated. Strain BG283 exhibited the highest genetic similarity to strain Pla107 when using loci gyrB, $r p o D, c t s$, and pgi. There were no amplicons for loci $a c n$ and $p f k$; and for locus gap $A$ exhibited the highest similarity to pathovar syringae. This suggests that this strain may be classified as such but does not have to belong to pathovar lachrymans. Strains LMG5070 and BG966 in all tested MLST loci showed the highest similarity to pathovar lachrymans strain Pla106 and to pathovar tomato. Strain 2905 confirmed the highest similarity to pathovar syringae in all tested MLST loci. The same result was obtained for strain WW4/02 (although this does not correlate with the pathogenicity tests) and for strain WK1/02 (except for gyrB locus, where it was

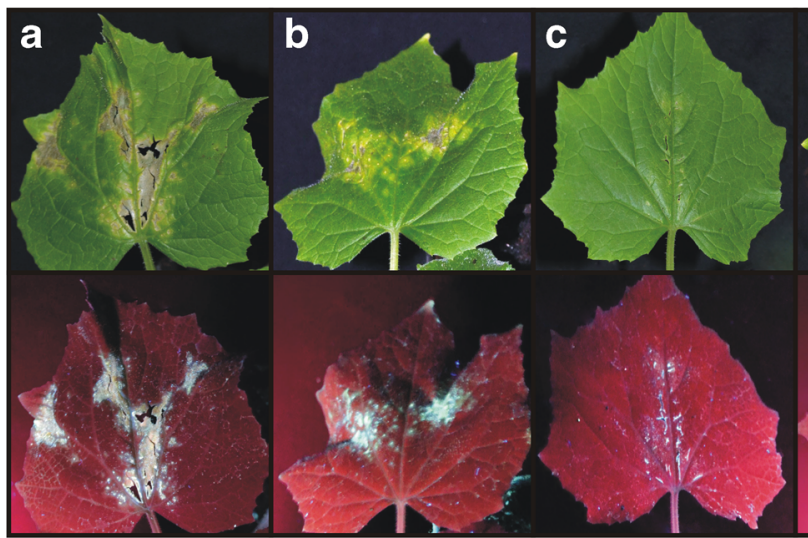

Fig. 2 The results of the pathogenicity and virulence tests performed on cucumber leaves of susceptible line B. Pictures were taken under day light (upper line) and under UV light (lower line-red leaves). The following strains are presented: a - Psl 814/98, b - Psl BG966, c - Psl BG283, d - Pss WW27/01, e - d
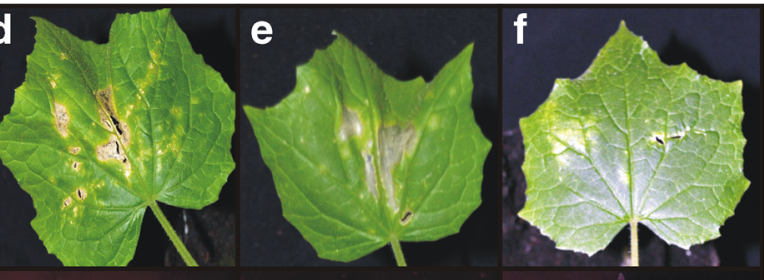

Pss WK1/02, f-Pf WH2/01. All strains were tested on line B - susceptible to angular leaf spot. Leaves were sprayed with inoculum containing $1 \times 10^{7} \mathrm{CFU} \mathrm{ml} \mathrm{m}^{-1}$ and results were recorded 7 days after inoculation 
similar also to pathovar pisi). Most of the strains that exhibited high similarity to pathovar syringae in 5 or 6 loci (i.e. BG913, CCB37/09, CCM2858, WW17/01, WW27/01, WW245/02) showed similarity to pathovar aptata at the pfk locus, and to pathovar pisi at the acn locus (strains WW17/01, WW27/01, and WW254/02). Strain PD2021 showed high similarity to pathovar syringae at 5 loci, failed to produce amplicons at the acn locus and showed high similarity to pathovar pisi at the $p f k$ locus. Four strains: PD3662, WH6/01, WM2/02, and YPG 1293, exhibited similarity to various pathovars at various MLST loci, that is to lachrymans (Pla106 and/ or Pla107), syringae, tomato, maculicola, aesculi, actinidiae, or P.fluorescens. Therefore classification of these strains into one certain pathovar was not possible. Three strains in our collection (PD2760, WH1/01, and WH2/02) turned out to be P.fluorescens strains or at least exhibited the highest genetic similarity to this species at 6 MLST loci for PD2760, 5 loci for WH1/ 01 and 3 MLST loci for WH2/01.

Analysis of genetic similarity Sequences of all MLST loci were used to construct phylogenetic trees (dendrograms) of genetic similarity. Based on the constructed dendrograms and alignment results collected strains were divided into four main groups (Figs. 5, 6 and 7). The first main group consisted of strains that belonged to pathovar lachrymans (strains 814/98, BG283, BG966, CCM2857, and LMG5070). These strains may be further divided into two separate clusters. The first cluster consisted of strains 814/98, BG283 and CCM2857, genetically very similar to each other, as well as to reference lachrymans strain Pla107 (JGI database). However, they differed in pathogenicity on cucumber, as strain BG283 exhibited only very week virulence. The second cluster consisted of two strains of P.s. pv. lachrymans: BG966 and LMG5070. These strains were very similar to each other and to reference lachrymans strain Pla106 (Figs. 6 and 7). The second main group is composed of pathovar syringae strains. This group consists of BG913, CCB37/09, CCM2858, PD2021, WK1/02, WW17/01, WW27/01, WW254/02, and WW4/02 and the reference syringae strain 2905 (Figs. 6 and 7). In this group, strain WW4//02 is an outlier, and strains WW17/01 and WW27/01, as well as PD2021 and CCB37/09 form two sub-groups (Fig. 7); this classification correlates with pathogenicity test results. The third main group consisted of three strains of P.fluorescens. The strains PD2760, WH1/01, and WH2/
01 were classified as P.fluorescens based on the high genetic similarity to sequences of this species deposited at the JGI database. These strains exhibit high genetic similarity to each other, and form a separate branch on dendrograms (Fig. 5, 6 and 7). The last group (PD3662, WH6/01, WM2/02, and YPG 1293) contains strains that do not exhibit similarity to any given pathovar. However, in pathogenicity tests these strains show similarities, and MLST assays form a separate dendrogram branch for them (Fig. 7).

Presence of plasmids Either plasmids or mega-plasmids were detected in 10 strains (Fig. 3). However, each strain contained a different set of plasmids. The presence or lack of plasmids, and their number and/or length, did not correlate with pathogenicity tests or with molecular

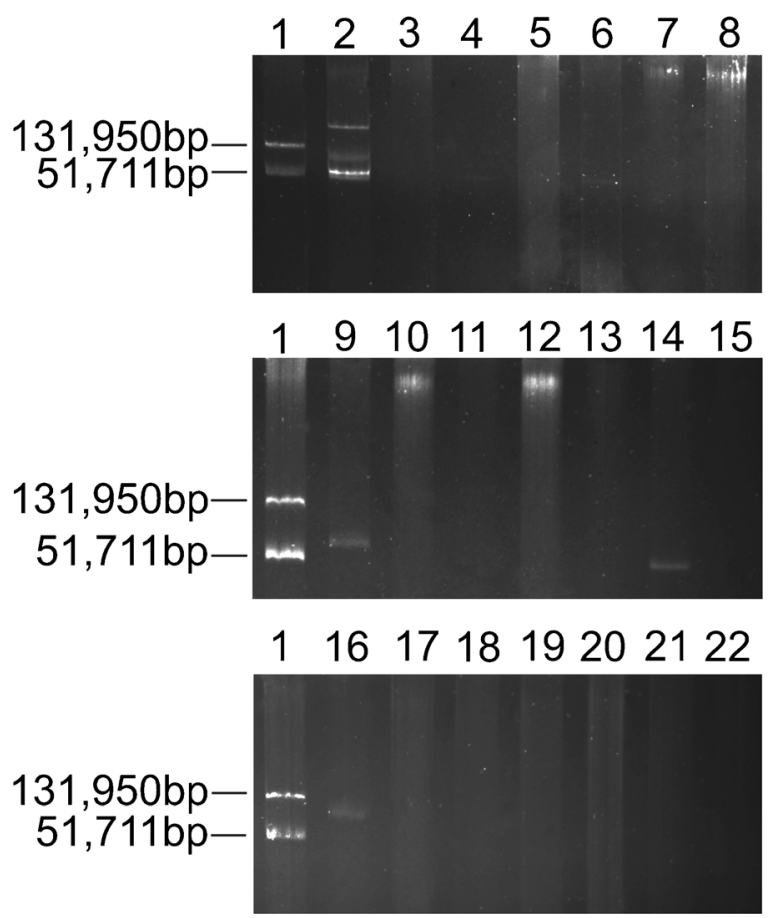

Fig. 3 The plasmid bands isolated from the collected Pseudomonas strains together with a positive control. Eckhardt gels for the 23 Pseudomonas sp. strains. Lane 1 - a positive control Pseudomonas syringae pv. phaseolicola 1448A strain (contains two plasmids of know size $-51,711 \mathrm{~kb}$ and $131,950 \mathrm{~kb}$ ), than the collected strains: lane 2 - Psl 814/98, lane 3 - Psl CCM2857, lane 4 - Psl BG283, lane 5 - Psl LMG5070, lane 6 - Psl BG966, lane 7 - Pss WK1/02, lane 8 - Pss WW254/02, lane 9- Pss BG913, lane 10 - Pss CCB37/09, lane 11 - Pss CCM2858, lane 12 - Pss PD2021, lane 13 - Pss 2905, lane 14 - Pss WW17/01, lane 15 Pss WW27/01, lane 16 - Pss WW4/02, lane 17 - Pf PD2760, lane 18 - Pf WH1/01, lane 19 - Pf WH2/01, lane 20 - P.sp. PD3662, lane 21 - P.sp. WM2/02, lane 22 - P.sp. WH6/01 
characterizations. Strain $814 / 98$ possessed four plasmids estimated to be about $40 \mathrm{~kb}, 50 \mathrm{~kb}, 100 \mathrm{~kb}$, and $200 \mathrm{~kb}$ in size. The other strains possessed one plasmid each: strains BG283, BG966, and WW17/01 had a plasmid about $40-50 \mathrm{~kb}$ in size, strain BG913 about $80-90 \mathrm{~kb}$, and strain WW4/02 about $100 \mathrm{~kb}$ in length. Strains WK1/02, WW254/02, CCB37/09, and PD2021 likely possessed a mega-plasmid which showed as a smeared high molecular weight band on the gel. Plasmid detection and visualisation was performed in a comparison to referenced strain P.s. pv. phaseolicola 1448A (Fig. 3). There was no obvious association between plasmid presence and strain pathogenicity or virulence.

\section{Discussion}

Genetic characterization and clustering, as well as fingerprinting of plant pathogenic bacteria by various molecular methods has been the subject of numerous papers (Versalovic et al. 1994; Weingart and Völksch 1997; Sarkar and Guttman 2004; Inoue and Takikawa 2006; Olczak-Woltman et al. 2007; Lee et al. 2012; Martín-Sanz et al. 2012). These studies showed that the MLST technique and rep-PCR are useful as methods for identification and classification of strains belonging to Pseudomonas syringae (Hwang et al. 2005; Louws et al. 1994). Therefore we decided to use these methods to group Pseudomonas strains isolated primarily from cucumber and kept in our Department's collection.

The genetic diversity of Pseudomonas strains isolated from cucumber and other cucurbit plants was assessed using the MLST technique, rep-PCR method, and amplification of the ITS1 region. The last, however, is not very useful in $P$. syringae pv. lachrymans diagnostics due to the multiple copies of the ITS1 region and the intergenomic DNA variation in this region.

The MLSTs of seven housekeeping genes chosen for use in this study have been known to reveal higher genetic diversity within collection of Pseudomonas strains than rep-PCR fingerprinting (Ferrante and Scortichini 2010). In this study we confirmed, that the MLST method is indeed a powerful tool for accurate strain clustering that correlates well with both pathogenicity and virulence assessments.

One of the objectives of this study was identification of an efficient technique for differentiation of pathovar lachrymans strains from among other strains isolated from cucumber plants. Moreover, we investigated the presence of plasmids in pathovar lachrymans and looked for a correlation between plasmid presence and virulence. We grouped and characterized the pathovar lachrymans strains with regard to pathogenicity and molecular tests results. We want to stress that it was not easy to collect strains of pathovar lachrymans because many strains isolated from Cucumis species turned to belong to pathovar syringae.

According to the results, the sequencing, clustering and alignment analysis of our collected cucurbit strain collection allows their division into four main groups. The first main group consists of strains that belong to pathovar lachrymans. These strains differ in the level of virulence and ERIC- and REP-PCR fingerprinting patterns (Figs. 2 and 4). Strains 814/98 and CCM2857 are the most virulent. The analysis of the MLST amplicons showed their high genetic similarity. The product of amplification of the $h r p Z$ gene fragment was present in both strains. Although they differ in the presence or absence of plasmids (four in 814/98 and none in CCM2857), they can be treated as a basic cluster for pathovar lachrymans based on the pathogenicity tests. The alignment with the JGI database sequence indicated high similarity to the lachrymans strain Pla107 that was characterized as highly virulent (Baltrus et al. 2011). The high virulence of both strains and difference in plasmids content suggest no correlation between plasmids presence and virulence for pathovar lachrymans.

Two strains: LMG5070 and BG966 that showed high molecular similarity to each other and caused similar, but week symptoms on cucumber, did not produce the $h r p Z$ gene fragment. Sequence alignment to strains deposited in the JGI database indicated significant similarity to pathovar lachrymans strain Pla106 (both for the MLST and the ITS1) described as less virulent and genetically separate from strain Pla107 (Baltrus et al. 2011). As before, despite of several attempts, it was not possible to isolate the same plasmids in both of these strains. In contrast to Pla107 and strains 814/98 and CCM2857, both strain Pla106 and strains LMG5070 and BG966 showed very high genetic similarity to pathovar tomato. We suggest therefore, that there are two different types of P.s. pv. lachrymans strains, that correspond to the Pla107 or Pla106 type respectively (Baltrus et al. 2011). Strains Pla107-like cause more developed symptoms on cucumber leaves, and exhibit some genetic similarity to pathovar syringae. Strains Pla106-like, are molecularly similar to pathovar tomato, 


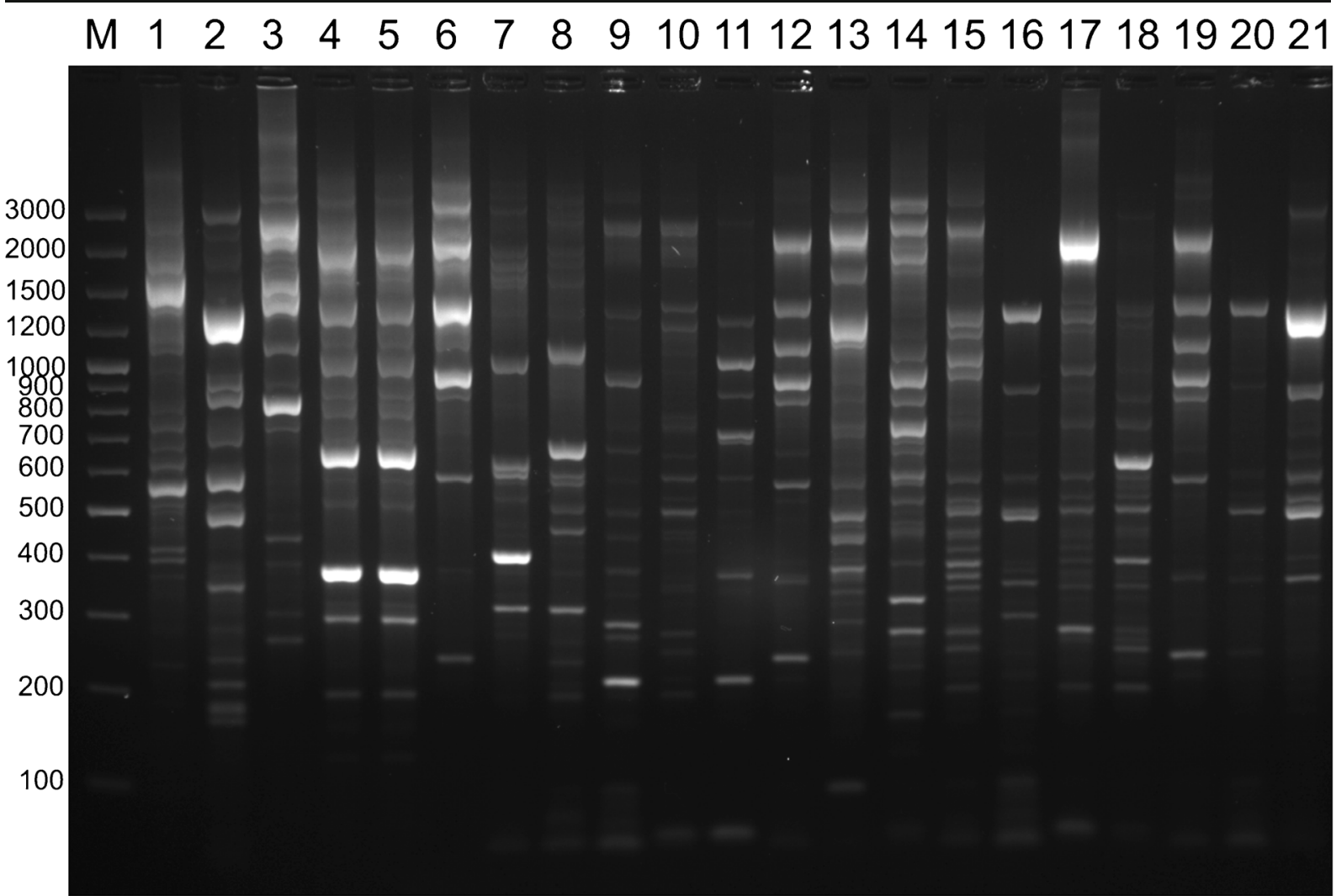

Fig. 4 The ERIC PCR fingerprinting pattern of the collected Pseudomonas strains. Lane M - 100 bp DNA molecular weight standard. Lines 1-21 - the following bacterial strains: lane $1-$ Psl 814/98, lane 2 - Psl CCM2857, lane 3 - Psl BG283, lane 4 - Psl LMG5070, lane 5 - Psl BG966, lane 6 - P.sp. PD3662, lane 7 P.sp. WM2/02, lane 8 - P.sp. WH6/01, lane 9 - Pss 2905, lane $10-$
Pss CCM2858, lane 11 - Pss BG913, lane 12 - Pss PD2021, lane 13 - Pss CCB37/09, lane 14 - Pss WW4/02, lane 15 - Pss WW17/01, lane 16 - Pss WW27/01, lane 17 - Pss WK1/02, lane 18 - Pss WW254/02, lane 19 - Pf PD2760, lane 20 - Pf WH1/01, lane 21 - Pf WH2/01

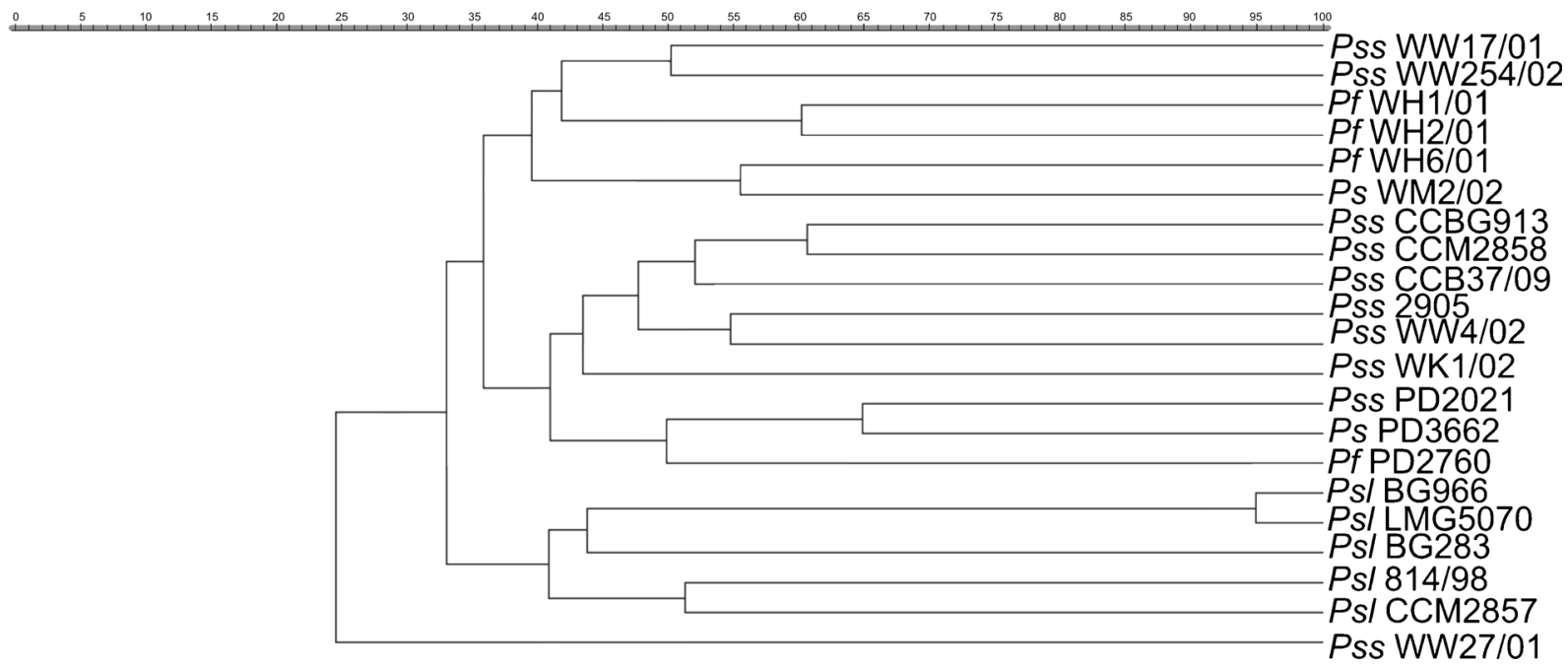

Fig. 5 The dendrogram of the genetic similarity (\%) of the collected strains based on the ERIC PCR fingerprinting. The dendrogram was constructed using GelCompare II software, using the Dice coefficient and the UPGMA clustering method 
a

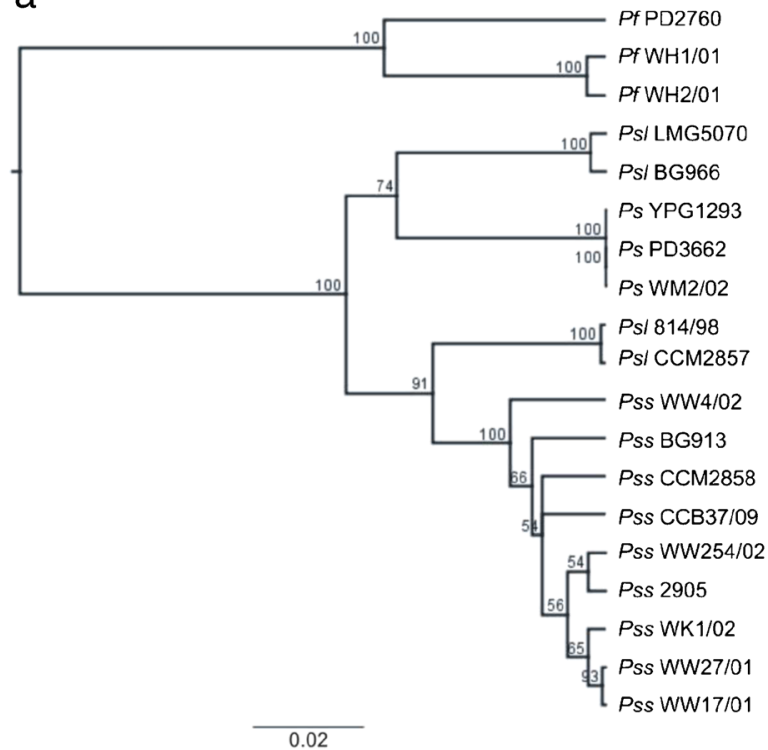

C

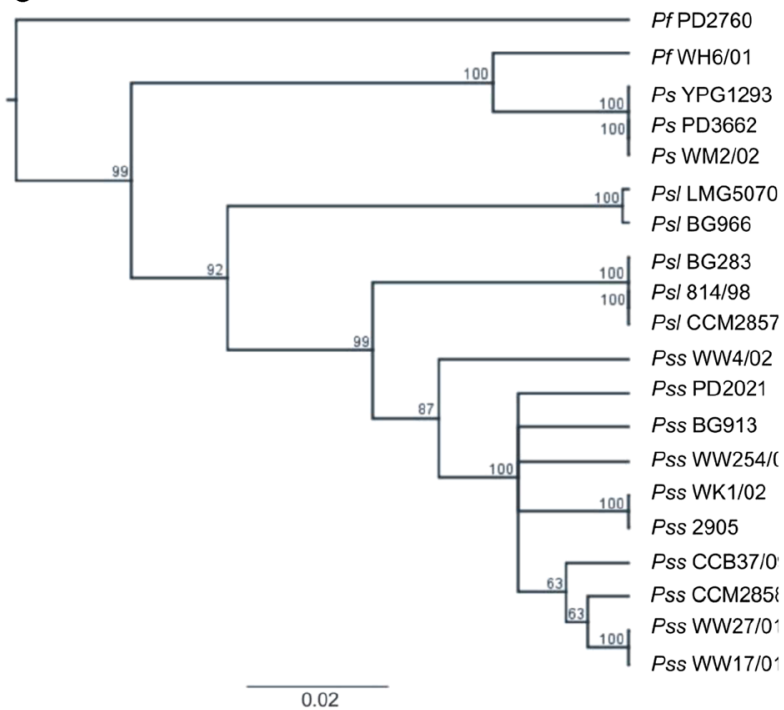

Fig. 6 The dendrograms of the genetic similarity (\%) of the collected bacterial strains based on the selected MLST loci. a $a c n, \mathrm{~b}-\operatorname{gap} A, \mathrm{c}-g y r B, \mathrm{~d}-r p o D$. Each dendrogram was

are much less virulent on cucumber, and cause only weak symptoms.

Strain BG283 posed some problems with classification. This strain produced the $h r p Z$ gene fragment, indicating high similarity to Pla107 strain type and in the MLST-based dendrogram was grouped into pathovar lachrymans type Pla107, but possessed one plasmid of the same length as BG966 (type Pla106), and in the repPCR based dendrogram was grouped into type Pla106 b

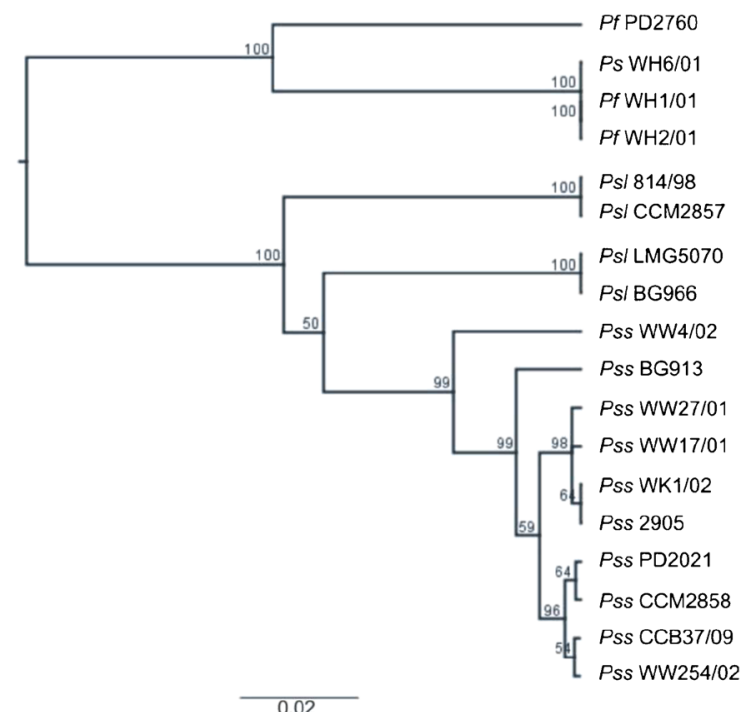

d

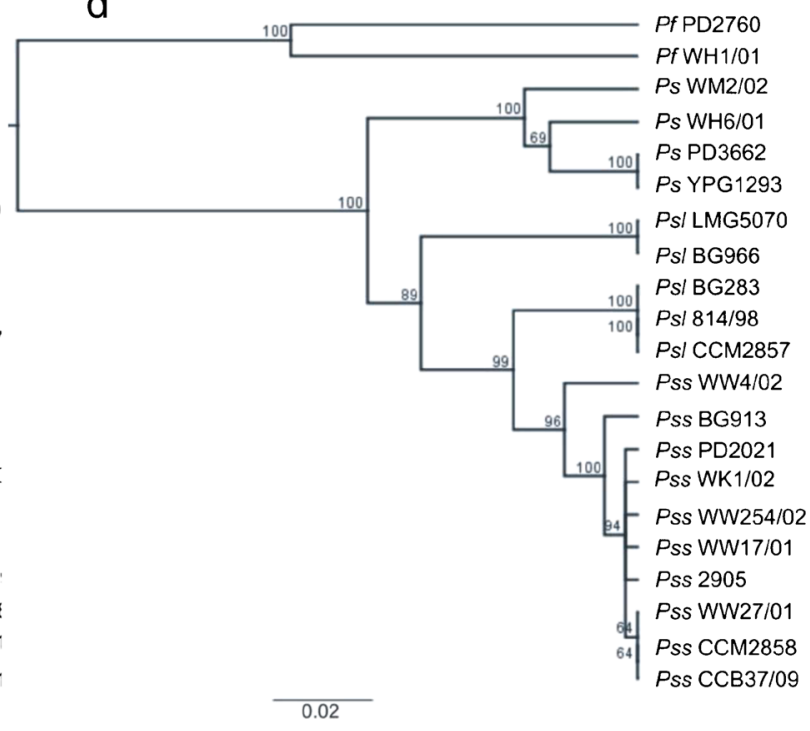

constructed using Geneious R7 software, with the Tamura-Nei evolutionary model and the UPGMA clustering method

(Figs. 5, 6 and 7). However, since it exhibited extremely low level of virulence on cucumber and no HR on tobacco leaves (Fig. 1) this classification is not clear. Perhaps strain BG283 is lachrymans, but lost its virulence, or maybe it even does not belong to pathovar lachrymans.

The second main group consists of strains that are unequivocally pathovar syringae. The occurrence of this pathovar on cucumber, and its characteristics consisting of atypical numerous pinpoint chlorotic lesions, or dry 


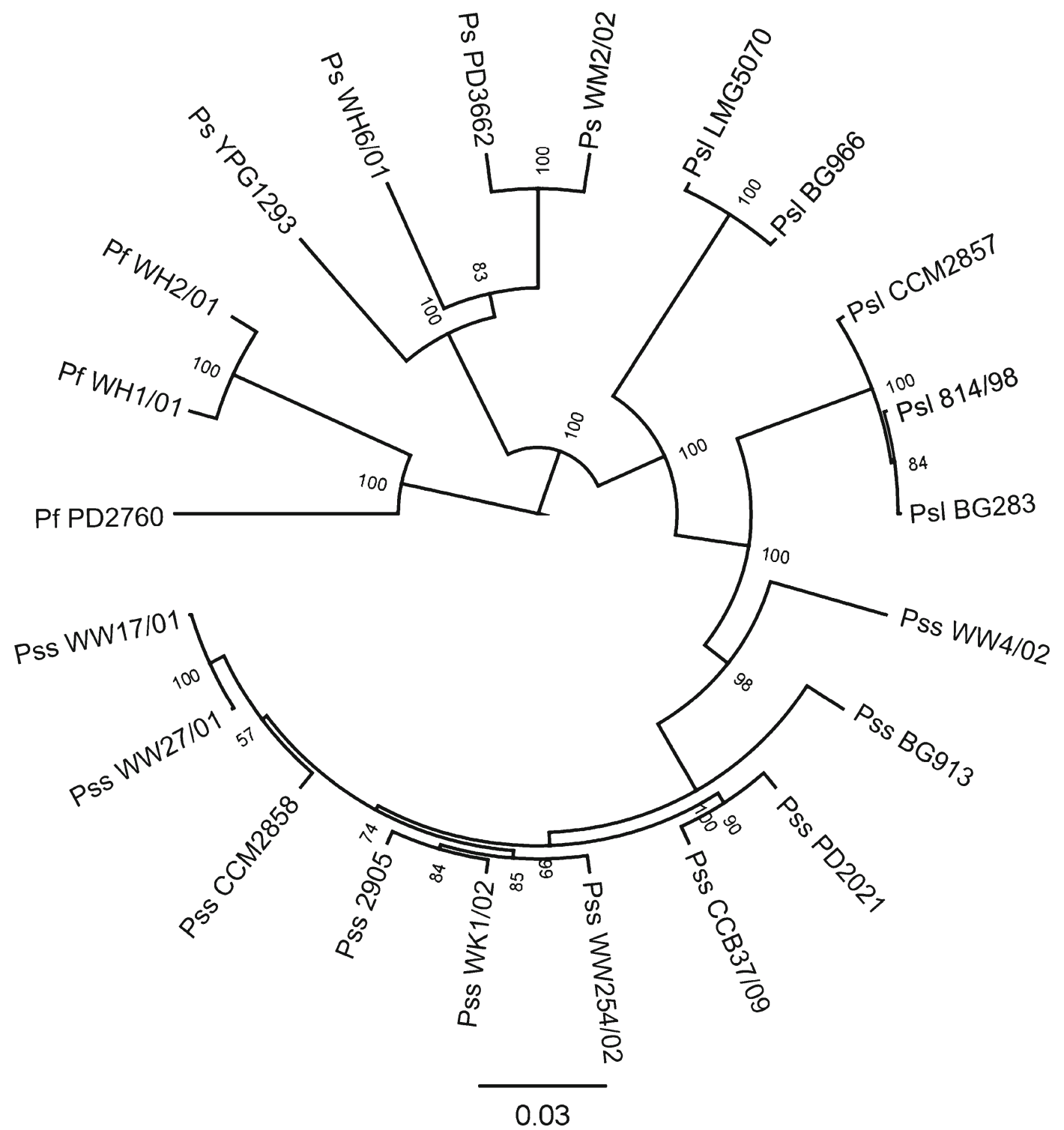

Fig. 7 The dendrogram of the genetic similarity (\%) of the collected bacterial strains based on the results of all seven analyzed in this study MLST loci together. The dendrogram was constructed

necrotic lesions without water-soaking has been described previously (Olczak-Woltman et al. 2007), and the classification into pathovar syringae has been verified by amplification of the $s y r B$ gene fragment (OlczakWoltman et al. 2007). In this study ten strains were classified as pathovar syringae (Fig. 7). These strains may further be divided into sub-groups. The reference strain P.s. pv. syringae 2905, together with cucumber strains BG913, WW17/01, WW27/01, and WW254/02 cause numerous pinpoint, chlorotic or lightly-coloured using Geneious R7 software, with the Tamura-Nei evolutionary model and the UPGMA clustering method

necrotic lesions on cucumber leaves. These symptoms were most intensive for BG913 and less intensive in the case of WW17/01 and WW27/01 (Fig. 2d). Interestingly, partly similar symptoms were caused by pathovar lachrymans strains LMG5070 and BG966.

Strains CCB37/09, PD2021, and WK1/02 caused large, dry, lightly-coloured necrotic lesions without chlorosis on cucumber leaves (Fig. 2e). Strain WK1/02 has been previously classified as more distant from the 2905 strain than the other pathovar syringae strains 
(Olczak-Woltman et al. 2007). The other two strains (CCM2858 and WW4/02) genetically similar $100 \%$ to strains of pathovar syringae deposited at the JGI database, differ dramatically from the others in terms of the symptom type on cucumber. At the one end of the spectrum, strain CCM2858 was one of the most virulent in the collection and, at the other end, strain WW4/02 displayed nearly no virulence. Finally, there are three strains in our collection that caused either very week or no specific symptoms on cucumber, caused no HR on tobacco, and were classified into P.fluorescens, as they showed high genetic similarity to sequences of this species deposited in the JGI database.

The MLST loci used in this study were used previously as phylogenetic markers. They appear to provide a sound method for classification of Pseudomonas strains isolated from cucumber. The gyr $B$-based phylogenetic tree for the local isolates was topologically almost identical to the tree based on the rep-PCR fingerprinting, while the phylogenetic tree based on the rpoB and rpoD gene sequences revealed clearly different patterns of variation (Sarris et al. 2012). Our results indicate that although the $g y r B$ is indeed one of the best markers for P.syringae pv. lachrymans, each method produces a somewhat different phylogenetic tree (Figs. 5 and 6) and perhaps the most reliable tree is obtained when several phylogenetic trees are combined into one (Fig. 7). Based on the ERIC and BOX PCR amplifications, strains belonging to P.s. pv. syringae appeared as the most heterogeneous and intermingled in relation to host plant, year and place of isolation (Weingart and Völksch 1997; Scortichini et al. 2003; Kalużna et al. 2010). We conclude that the best reflection of the strains biological properties, i.e. pathogenicity and virulence, are displayed when applying the MLST method.

There was some confusion and unexpected results when we analyzed the plasmid content. There are publications that suggest pathogenicity islands are plasmidborne (Jackson et al. 1999; Gibbon et al. 1999; Ma et al. 2007). However, in this study some highly virulent strains had no plasmid, and some non-virulent strains had a plasmid (Fig. 3). This leads to a conclusion that in the case of Pseudomonas syringae pv. lachrymans, additional analysis should be performed to better describe the plasmid/virulence relationship.

Overall, the results of this study indicate that pathogenicity tests combined with molecular analysis are accurate in differentiation and classification of plant pathogenic bacteria. We demonstrated that $P$. syringae pv. lachrymans is genetically diverse, which was exhibited by both pathogenicity and molecular tests. In case of some strains isolated from cucumber it is difficult to say which pathovar they belong to, because the sequences of various loci exhibit similarity to genomes of different strains. In general, the obtained results confirm the genome architecture diversity and dynamics of P.syringae shown by Baltrus et al. (2011). There is a great need to sequence more genomes of different pathovars of the plant pathogen Pseudomonas syringae to further study its complex composition.

Acknowledgments We express our gratitude to all the scientist and organizations for sharing with us their bacterial strains. We thank Dr. Bart Geraats from Nunhems Netherlands, Haelen, The Netherlands; Dr. Maria Bergsma-Vlami from the National Reference Centre, Plant Protection Service, Wageningen, The Netherlands; Dr. Jaroslav Horký and colleges from the AGRI, Olomouc, Czech Republic; Dr. Piotr Sobiczewski from the Research Institute of Pomology and Floriculture in Skierniewice, Poland; Dr. Jesus Murillo from Laboratorio de Patologia Vegetal, Agraria Universidad Publica de Navarra, Pamplona, Spain (for strain 1448A of P. syringae pv. phaseolicola); the Microbiology Laboratory in Gent, Belgium; and Institute of Plant Protection, Poznan, Poland. We also thank Dr. Dariusz Bartosik and Dr. Jakub Czarnecki from the Department of Bacterial Genetics of University of Warsaw for help with plasmid detection.

Open Access This article is distributed under the terms of the Creative Commons Attribution License which permits any use, distribution, and reproduction in any medium, provided the original author(s) and the source are credited.

\section{References}

Baltrus, D. A., Nishimura, M. T., Romanchuk, A., Chang, J. H., Mukhtar, M. S., Cherkis, K., Roach, J., Grant, S. R., Jones, C. D., \& Dangl, J. L. (2011). Dynamic evolution of pathogenicity revealed by sequencing and comparative genomics of 19 Pseudomonas syringae isolates. PLoS ONE, 7, 1-22.

Bradbury, J. F. (1986). Guide to plant pathogenic bacteria. (Ferry Lane, Kew, Surrey, CAB International Mycological Institute), pp.154-177.

De Bruijn, F. J. (1992). Use of repetitive (repetitive extragenic palindromic and enterobacterial repetitive intergeneric consensus) sequences and the polymerase chain reaction to fingerprint the genomes of Rhizobium meliloti isolates and other soil bacteria. Applied and Environmental Microbiology, 58, 2180-2187.

Eckhardt, T. (1978). A rapid method for the identification of plasmid deoxyribonucleic acid in bacteria. Plasmid, 1, 584 588.

Ferrante, P., \& Scortichini, M. (2010). Molecular and phenotypic features of Pseudomonas syringae pv. actinidiae isolated during recent epidemics of bacterial canker on yellow 
kiwifruit (Actinidia chinensis) in central Italy. Plant Pathology, 59, 954-962.

Gibbon, M. J., Sesma, A., Canal, A., Wood, J. R., Hidalgo, E., Brown, J., Vivian, A., \& Murillo, J. (1999). Replication regions from plant-pathogenic Pseudomonas syringae plasmids are similar to ColE2-related replicons. Microbiology, 145, 325-334

Hwang, M. S., Morgan, R. L., Sarkar, S. F., Wang, P. W., \& Guttman, D. S. (2005). Phylogenetic characterization of virulence and resistance phenotypes of Pseudomonas syringae. Applied and Environmental Microbiology, 71, 5182-5191.

Inoue, Y., \& Takikawa, Y. (2006). The $h r p Z$ and $h r p A$ genes are variable, and useful for grouping Pseudomonas syringae bacteria. Journal of General Plant Pathology, 72, 26-33.

Jackson, R. W., Athanassopoulos, E., Tsiamis, G., Mansfield, J. W., Sesma, A., Arnold, D. L., Gibbon, M. J., Murillo, J., Taylor, J. D., \& Vivian, A. (1999). Identification of a pathogenicity island, which contains genes for virulence and avirulence, on a large native pathovar phaseolicola. Proceedings of the National Academy of Sciences, 96, 10875-10880.

Joardar, V., Lindeberg, M., Jackson, R. W., \& Buell, C. R. (2005). Whole-genome sequence analysis of Pseudomonas syringae pv. phaseolicola 1448A reveals divergence among pathovars in genes involved in virulence and transposition. Journal of Bacteriology, 187, 6488-6498.

Kalużna, M., Ferrante, P., Sobiczewski, P., \& Scortichini, M. (2010). Characterization and genetic diversity of Pseudomonas syringae from stone fruits and hazelnut using repetitive-PCR and MLST. Journal of Plant Pathology, 92, 781-787.

Klement, Z., Mavridis, A., Rudolph, K., \& Vidaver, A. (1990). Inoculation of plant tissues. In Z. Klement, K. Rudolph, \& D. S. Sands (Eds.), Methods in phytobacteriology (pp. 94-124). Budapest: Akadémiai Kiadó.

Lee, Y. S., Koh, H. S., Sohn, S. H., Koh, Y. J., \& Jung, J. S. (2012). Genetic diversity among Pseudomonas syringae pv. morsprunorum isolates from Prunus mume in Korea and Japan by comparative sequence analysis of 16S rRNA gene. Plant Patholology Journal, 28, 295-298.

Louws, F. J., Fulbright, D. W., Stephens, C. T., \& de Bruijn, F. J. (1994). Specific genomic fingerprints of phytopathogenic Xanthomonas and Pseudomonas pathovars and strains generated with repetitive sequences and PCR. Applied Environmental Microbiology, 60, 2286-2295.

Ma, Z., Smith, J. J., Zhao, Y., Jackson, R. W., Arnold, D. L., Murillo, J., \& Sundin, G. W. (2007). Phylogenetic analysis of the pPT23A plasmid family of Pseudomonas syringae. Applied and Environmental Microbiology, 73, 1287-1295.

Maiden, M. C., Bygraves, J. A., Feil, E., Morelli, G., Russell, J. E., Urwin, R., Zhang, Q., Zhou, J., Zurth, K., Caugant, D. A., Feavers, I. M., Achtman, M., \& Spratt, B. G. (1998). Multilocus sequence typing a portable approach to the identification of clones within populations of pathogenic microorganisms. Proceedings of the National Academy of Sciences USA, 95, 3140-3145.

Maj, A., Dziewit, L., Czarnecki, J., Wlodarczyk, M., Baj, J., Skrzypczyk, G., Giersz, D., \& Bartosik, D. (2013). Plasmids of carotenoid-producing paracoccus spp.
(Alphaproteobacteria) - structure, diversity and evolution. PLoS ONE, 8, e80258.

Manceu, C., \& Horvais, A. (1997). Assessment of genetic diversity among strains of Pseudomonas syringae by PCRrestriction fragment length polymorphism analysis of rRNA operons with special emphasis on $P$. syringae pv. tomato. Applied and Environmental Microbiology, 63, 498-505.

Martín-Sanz, A., Pérez de la Vega, M., Murillo, J., \& Caminero, C. (2012). Genetic, biochemical and pathogenic diversity of Pseudomonas syringae pv. pisi strains. Plant Pathology, 61, 1063-1072.

O‘Brien, H. E., Desveaux, D., \& Guttman, D. S. (2011). Nextgeneration genomics of Pseudomonas syringae. Current Opinion in Microbiology, 14, 1-7.

Olczak-Woltman, H., Masny, A., Bartoszewski, G., Plucienniczak, A., \& Niemirowicz-Szczytt, K. (2007). Genetic diversity of Pseudomonas syringae pv. lachrymans strains isolated from cucumber leaves collected in Poland. Plant Pathology, 56, 373-382.

Olczak-Woltman, H., Schollenberger, M., Mądry, W., \& Niemirowicz-Szczytt, K. (2008). Evaluation of cucumber (Cucumis sativus L.) cultivars grown in Eastern Europe and progress in breeding for resistance to angular leaf spot (Pseudomonas syringae pv. lachrymans). European Journal of Plant Pathology, 122, 385-393.

Sarkar, S. A., \& Guttman, D. S. (2004). Evolution of the core genome of Pseudomonas syringae, a highly clonal, endemic plant pathogen. Applied and Environmental Microbiology, 70, 1999-2012.

Sarris, P. S., Trantas, E. A., Mpalantinaki, E., Ververidis, F., \& Goumas, D. E. (2012). Pseudomonas viridiflava, a multi host plant pathogen with significant genetic variation at the molecular level. PLoS ONE, 4, 1-12.

Scortichini, M., Marchesi, U., Dettori, M. T., \& Rossi, M. P. (2003). Genetic diversity, presence of the $s y r B$ gene, host preference and virulence of Pseudomonas syringa pv. syringae strains from woody and herbaceous host plants. Plant Pathology, 52, 277-286.

Sorensen, K. N., Kim, K.-H., \& Takemoto, J. Y. (1998). PCR detection of cyclic lipodepsinonapeptide-producing Pseudomonas syringae pv. syringae and similarity of strains. Applied and Environmental Microbiology, 64, 226-230.

Urwin, R., \& Maiden, M. C. (2003). Multi-locus sequence typing: a tool for global epidemiology. Tends in Microbiology, 11, 479-487.

Versalovic, J., Koeuth, T., \& Lupski, J. R. (1991). Distribution of repetitive DNA sequences in eubacteria and application to fingerprinting of bacterial genomes. Nucleic Acids Research, $19,6823-6831$.

Versalovic, J., Schneider, M., de Bruijn, F. J., \& Lupski, J. R. (1994). Genomic fingerprinting of bacteria using repetitive sequence-based polymerase chain reaction. Methods in Molecular and Cellular Biology, 5, 25-40.

Weingart, H., \& Völksch, B. (1997). Genetic fingerprinting of Pseudomonas syringae pathovars using ERIC-, REP-, and IS50-PCR. Journal of Phytopathology, 145, 339-334.

Young, J. M., Saddler, G. S., Takikawa, Y., De Boer, S. H., Vauterin, L., Gardan, L., Gwozdyak, R. I., \& Stead, D. E. (1996). Names of plant pathogenic bacteria 1864-1995. Review of Plant Pathology, 75, 721-763. 